died in a few days for all our every effort either operative or conservative.

It is of paramount interest to have made it clear that the cardiac output differs significantly between the survival and fatal, and that the difference can be noted as early as the first 12 hours following head injury.

2) Correlation of the cardiac indices with oxygen consumption.

Correlation of the cardiac indices with oxygen consumption $\left(\mathrm{VO}_{2} / \mathrm{m}^{2}\right)$ was significant.

3) Correlation of cardiac indices with blood volumes.

The blood volume, below the plateau level of 2.0 to $2.5 \mathrm{l} / \mathrm{m}^{2}$, decreased keeping pace with the decrease in the cardiac output.

4) Correlation of the cardiac indices with respiratory insufficiency.

The cardiac indices appeared to be not always correlated with $\mathrm{PaO}_{2}, \mathrm{~A}-\mathrm{aDO}$, and Qs/Qt. However, in some identical patients, the cardiac indices decreased significantly when receiving the assisted or controlled respiration of $100 \% \mathrm{O}_{2}$, compared with the time of spontaneous room air respiration.

5) Correlation of the cardiac indices with the difference of oxygen content in the arterial blood and mixed venous blood.

The increased $\mathrm{CaO}_{2}-\mathrm{CvO}_{2}$, which is said to imply the formation of systemic shunts, was inversely proportional to the increase in the cardiac output.

\title{
82. The Nation-Wide Study of Traumatic Sequela Cases by Traffic Accidents Conducted from Viewpoints of Neurology and Neurological Surgery
}

\author{
Shigeo Watanabe, M. D. \\ Department of Neurosurgery of National \\ Tachikawa Hospital and Chuo Helath \\ Insurance Hospital \\ Takeshi Tакаомі, M. D. \\ National Institute of Mental Health \\ Mitsuaki Ishikawa, M. D. \\ The Japanese Council of Traffic Science
}

This is a statistical report on the results of our nation-wide study conducted for approximately two years of the 'Traumatic Sequela cases' by traffic accidents coming under the provisions of the Automobile Liability Security Law.

In carrying out this survey, all Japan is divided into fifteen geographical regions, and made a technical study strictly from the standpoints of 'Neurological surgery,' 'Neurology' and 'Psychiatry.'

The gist of the findings of our study is as follows:-

Of the total cases, those who developed symptoms of 'Unconciousness' amounted to $52.6 \%$, and of the first class cases, those who remained unconcious for more than 
24 hours accounted for $55.3 \% .37 .6 \%$ of the total cases were subject to 'Headaches,' and $51.4 \%$ of the first class cases showed the same symtoms. The half of the total cases complained of 'Occipitalgy.' $33.9 \%$ of the total cases showed the signs of either 'Nuchealgy' or 'Neck pain' or both, and of the first class cases, this percentage reached 63. Those who suffered from 'Visual distarbance' were $14.5 \%$ of the total cases and $33.5 \%$ of the first class cases. As to 'Hearing disturbance,' $8.6 \%$ of the total cases and $16.4 \%$ of the first class cases complained of the symptom, while as to 'Speech disorder' $5.7 \%$ of the total cases and $38.5 \%$ of the first class cases were the sufferers. Those who has 'Chewing disturbance' were $8.1 \%$ of the total cases and $20.6 \%$ of the first class cases. The cases of 'Vertigo' and 'Dizziness' caused by balance disturbance' were $8.1 \%$ of the total cases and $20.6 \%$ of the first class cases. The cases of 'Vertigo' and 'Dizziness' caused by balance disturbance amounted to $22.3 \%$ of the total figure and $58.3 \%$ of the first class cases. $78.4 \%$ of the total cases suffered from this symptom occasionally. $3.9 \%$ of the total cases and $15.3 \%$ of the first class cases came to be attacked by 'Epilepsy.' Those who showed the symptom of 'Abnormality of E. E. G.,' not accompanying cpileptic attack accounted for $3.9 \%$. This symptom was widely recognized throughout all classes of the cases reging from the first to the twelfth. 'Movement disorder of upper extremity' was prevalent among $8.5 \%$ of the total cases and $14.0 \%$ of the first class cases, while 'Movement disorder of lower extremity' was perceived among $15.6 \%$ of the enitre cases and $17.2 \%$ of the first class cases. and $38.8 \%$ of the first class cases. Those who had 'Subjective mental symptoms' were numerically caught as under:-

$35.7 \%$ of the entire cased and $80.5 \%$ of the first class cases were 'Nervous.' $24.9 \%$ of the total cases and $73.5 \%$ of the first class cases were suffering from 'Isomnia.' $28.2 \%$ of the total cases and $62.6 \%$ of the first class cases were 'Forgetful.' $28.6 \%$ of the total cases and $69.0 \%$ of the first class cases were 'Impaitinet.' $51.1 \%$ of the whole cases and $90.0 \%$ of the first class cases were 'Easy to get fatigued.'

As regards the character changes where 'Objective symptoms' ware apparent, the following results were obtained:-

$11.3 \%$ of the total cases and $20.6 \%$ of the first cases were 'Forgetful.' $4.3 \%$ of the total cases and $14.3 \%$ of the first class cases grew 'Senile.' $2.3 \%$ of the total cases and $9.7 \%$ of the first class cases were 'Untidy.' $14.4 \%$ of the total cases and $31.9 \%$ of the first class cases were 'Short tempered.' $2.3 \%$ of the total cases and $5.4 \%$ of the first class cases were 'Reserved.' $30 \%$ of the total cases and $5.8 \%$ of the first class cases developed character changes other than those which are stated above. 'Disturbance (Declining) in Sexual desire' were seen among 9.8\% of the total cases and $13.1 \%$ of the first class cases. $3.3 \%$ of the total cases of women were suffering from 'Irregular menses.'

All the cases of 'Traumatic sequelae' mentioned above are of more than four year-old 'Anamnesis.' The neurological and mental changes caused by them are rich in variety as given therein. Among these disorders there are such ones which requre neurosurgical treatments as 'Focus-epilepry,' 'Central motility disorder,' and 'Aphasia.' In any case, all of these neurological and mental changes need professional and special treatments. In these cases, the treatments of 'Neurology.' 'Neurosurgery' and 'Rehabilitation-medicine' should be stressed. 